\title{
Effect of Dissolved Oxygen on Aluminum Corrosion in Simulated Cooling Water for HVDC Systems at $50{ }^{\circ} \mathrm{C}$
}

\author{
Liangshou Hao ${ }^{1}$, Jiashui Dai ${ }^{1}$, Zhangqiang Huang ${ }^{1}$, Chaoyu Lei ${ }^{1}$, Feng Zheng ${ }^{1}$, Jiayang Li ${ }^{1}$, \\ Youping Fan ${ }^{2, *}$, Shengping Wang ${ }^{3, *}$ \\ ${ }^{1}$ Tianshengqiao Bureau, Extra High Voltage Power Transmission Company, China Southern Power \\ Grid (CSG), Xingyi 562400, China \\ ${ }^{2}$ School of Electrical Engineering and Automation, Wuhan University, Wuhan 430072, China \\ ${ }^{3}$ Faculty of Material Science and Chemistry, China University of Geosciences, Wuhan 430074, China \\ *E-mail: ypfan@whu.edu.cn, spwang@ cug.edu.cn
}

doi: $10.20964 / 2021.05 .20$

Received: 9 January 2021 / Accepted: 21 February 2021 / Published: 31 March 2021

\begin{abstract}
The corrosion behavior of aluminum in $50{ }^{\circ} \mathrm{C}$ deionized water with varying dissolved oxygen contents was studied. Compared with deionized water, an aqueous solution with dissolved oxygen promoted aluminum corrosion. With increasing dissolved oxygen content, the corrosion of the aluminum surface became more serious, and the corrosion resistance of the aluminum gradually decreased. When the oxygen content in the water was increased from $0 \mathrm{mg} \mathrm{L}^{-1}$ to $4.0 \mathrm{mg} \mathrm{L}^{-1}$, the aluminum corrosion potential decreased from $-1.282 \mathrm{~V}$ to $-1.503 \mathrm{~V}$, the corrosion current density increased from $1.987 \times 10^{-7} \mathrm{~A} \mathrm{~cm}^{-2}$ to $4.904 \times 10^{-7} \mathrm{~A} \mathrm{~cm}^{-2}$, and the charge transfer impedance decreased from $8.057 \times 10^{4} \Omega \mathrm{cm}^{-2}$ to 2.427 $\times 10^{4} \Omega \mathrm{cm}^{-2}$. The corrosion products for aluminum in water containing oxygen are $\mathrm{Al}(\mathrm{OH})_{3}$ and $\mathrm{Al}_{2} \mathrm{O}_{3}$, and the corrosion type is mainly pitting corrosion. The number of the pitting holes gradually increase with increasing oxygen content in the aqueous solution. Removing the dissolved oxygen from the cooling water of a valve cooling system with nitrogen is an effective method to limit corrosion of aluminum radiators and the scaling of grading electrodes in high-voltage direct current transmission systems.
\end{abstract}

Keywords: aluminum, erosion corrosion, dissolved oxygen, radiator, high voltage direct current

\section{FULL TEXT}

(C) 2021 The Authors. Published by ESG (www.electrochemsci.org). This article is an open access article distributed under the terms and conditions of the Creative Commons Attribution license (http://creativecommons.org/licenses/by/4.0/). 